\title{
Los Consejos de Salarios en Uruguay con el gobierno de la izquierda*
}

\author{
Luis Ibarra \\ Universidad de la República del Uruguay
}

\section{Resumen}

El artículo analiza los Consejos de Salarios organizados en Uruguay por el gobierno de izquierda. Procura demostrar que no son simplemente una vuelta atrás, desde la desregulación laboral hacia la institución clásica del compromiso social. Envuelven, por el contrario, una inversión de las relaciones del trabajo con el estado y el capital.

Palabras-clave: Sindicatos; gobierno de izquierda; Uruguay.

\begin{abstract}
The paper analyzes the wage councils organized by the left government of Uruguay. It suggests that there are not a simply turn back, from labor deregulation to the classic institution of social compromise. Instead, they represent a really inversion of the relations between labor, state, and capital.
\end{abstract}

Keywords: Trade unions; left government; Uruguay.

\section{Introducción}

$\mathrm{U}$

no de los rasgos más destacados del gobierno de la izquierda en Uruguay es, sin duda, la relación con el trabajo. El Frente Amplio puso fin a la desregulación del mercado laboral y restableció los Consejos de Salarios. La reaparición de esta institución típica del compromiso social parece un anacronismo, pero va acompañada también de cambios en sus características siguiendo las transformaciones del trabajo. El retorno a la negociación colectiva coincidió también con un crecimiento del producto y el aumento del empleo, sin embargo, estos aspectos sólo serán considerados aquí de manera lateral.

\footnotetext{
* Wage councils and the left governs in Uruguay

${ }^{1}$ Investigador del Instituto de Ciencia Política y docente de la Facultad de Ciencias Sociales de la Universidad de la República. Endereço para correspondências: Comisión Honoraria para la Lucha Antituberculosa, Av. 18 de Julio 2175, Montevideo, Uruguay (libarra@cpolit.edu.uy).
} 
Nuestro objetivo no es estudiar los efectos económicos y sociales de los cambios institucionales, sino buscar su causa eficiente en las relaciones entre los sujetos políticos.

El artículo analiza los Consejos de Salarios organizados por el gobierno del Frente Amplio. Procura demostrar que no son, simplemente, la actualización de una institución clásica del estado uruguayo, sino que envuelven, por el contrario, una inversión de las relaciones del trabajo con el estado y el capital. Empieza por delimitar el marco analítico, luego caracteriza a la institución clásica, recorre las modificaciones introducidas por la izquierda y, finalmente, reúne las conclusiones.

\section{El punto de vista del trabajo}

Diversas perspectivas teóricas enfocan la relación salarial destacando aspectos y problemas diferentes. Una primera clasificación distingue entre los puntos de vista que la consideran sólo como una relación de mercado y los que ven el vínculo entre trabajo y capital como una relación específica.

Es común considerar a la capacidad de trabajo como una mercancía. Oferta y demanda determinan, en este caso, los salarios y el empleo como ocurre con los precios y cantidades de cualquier mercancía. Las opiniones divergen aquí con respecto a la organización del mercado de trabajo.

El enfoque predominante en la década del noventa fue suprimir las interferencias en el mercado (WORLD BANK, 1995). Este punto de vista considera a las instituciones como una organización funcional, guiada por criterios de eficiencia. Critica la fijación de salarios mínimos y la legislación laboral protectora como factores que impiden el ajuste del mercado y producen efectos contrarios a los deseados. Espera que la desregulación disminuya los costos del trabajo y conduzca a un aumento de la demanda de empleo.

Con los años dos mil, en cambio, se extiende el rechazo de la informalidad como una amenaza al crecimiento económico y la integración social (BANCO MUNDIAL, 2007). Las críticas señalan que la desregulación, lejos de aumentar el empleo, en realidad redujo los salarios, afectó las condiciones de trabajo y produjo situaciones de exclusión social. Las instituciones tienen que ver, en esta perspectiva, con relaciones de poder asimétricas. Los enfoques vigentes presentan al trabajador como la parte más débil, 
consideran que el mercado acentúa las diferencias a favor del capital y requieren la mediación del estado, no para suprimir, sino para equilibrar la relación y redistribuir las rentas.

No se trata, sin embargo, de una vuelta atrás, que restablezca las antiguas normas, sino de regular unas condiciones de trabajo profundamente transformadas. La discusión sale de la disyuntiva entre regulación o desregulación, para desplazarse hacia la cuestión de los modos de regulación. Adquieren interés, entonces, enfoques que consideran el vínculo entre trabajo y capital como una relación particular, distinta del resto de las mercancías. Las diferencias refieren aquí a la reproducción o la ruptura de la relación.

La escuela de la regulación, por ejemplo, se caracterizó por estudiar las estructuras que permiten la reproducción de las relaciones sociales a pesar de su carácter contradictorio (BOYER, 2003). Considera a las instituciones como un resultado de luchas políticas, que regulan los conflictos sin suprimirlos, y ve la clave del desarrollo en el modo de regulación. Critica la flexibilización laboral y promueve una implicación de los trabajadores en el aumento de la productividad como base para reanudar los pactos sociales y orientar la acción del estado (LIPIETZ, 1997).

Las corrientes derivadas del obrerismo, en cambio, refieren la dinámica social al antagonismo de los sujetos y desarrollan el punto de vista del trabajo (TRONTI, 2001). Su concepto central es el de composición de clase: "definida por la composición 'técnica', es decir, por las formas tecnológicas de la producción y la organización del trabajo, y por la composición 'política', es decir, por la historia de luchas políticas, organización, por la mutación de necesidades y deseos" (NEGRI, 2002, p.162). El estado aparece aquí como la forma que domina la relación de clases y recibe las resistencias de los grupos subalternos. Desde esta perspectiva, los conflictos no consisten sólo en que los trabajadores aspiran a trabajar menos y ganar más, mientras que los empleadores quieren pagar menos por más trabajo. Están animados también por el deseo de escapar a la explotación y organizar la vida de manera autónoma.

El punto de vista del trabajo permite analizar los Consejos de Salarios no por sus efectos sobre el mercado de trabajo o la integración social, sino como una respuesta política a conflictos y sujetos particulares. Veremos, a continuación, las características de la institución clásica y luego los cambios introducidos por el gobierno del Frente Amplio. 


\section{Los Consejos de Salarios clásicos}

Los Consejos de Salarios consisten en "comisiones tripartitas, integradas por el gobierno, sindicatos y empleadores, constituidas por ramas de actividad, que tienen la facultad de fijar salarios mínimos"(ERMIDA, 2006).

Fueron creados a mediados del siglo XX como reacción a la formación en Uruguay de una clase obrera masiva. Los estudios del período señalan el crecimiento de la población urbana y un aumento en la cantidad de obreros industriales a partir de la década de 1930. Los aspectos técnicos de la organización del trabajo y los aspectos políticos de la historia de luchas, organización, necesidades y deseos definen, a su vez, una composición social particular (NEGRI, 2002). El taylorismo, la separación entre concepción y ejecución de las tareas, incorporó grandes masas de trabajadores no especializados a la producción en serie. Son una figura novedosa, ajena a las tradiciones proletarias del novecientos, pero altamente dinámica, que escapa de la miseria rural buscando una vida mejor y más libre. Estos sujetos protagonizaron un intenso ciclo de luchas y organización que recompuso el movimiento obrero, luego de la dispersión de los años treinta, bajo nuevas formas (ERRANDONEA y COSTABILE, 1969). Sindicatos de industria masivos, que reúnen a todos los trabajadores de una rama de actividad, incluyendo a los no calificados, reemplazaron a las sociedades de resistencia por oficios y emprendieron nuevas experiencias de centralización, basadas en la autonomía con respecto a partidos e ideologías políticas (RODRÍGUEZ, 1966).

Los Consejos de Salarios procuraron disciplinar a esa figura tumultuosa: organizarla como fuerza de trabajo, suprimir sus expresiones autónomas y subordinar sus necesidades y deseos al desarrollo del capital.

$\mathrm{El}$ antecedente directo es una investigación parlamentaria sobre las condiciones de vida de los trabajadores, presentada a la Cámara de Diputados en el año 1940. El informe describe una situación penosa y considera que, "sin lesionar el vigor de las industrias, se podría mejorar el nivel y el estilo de vida de la clase obrera" (RODRÍGUEZ, 1966, p.31). Con ese fin, propuso varias medidas que incluían la creación de comisiones paritarias, salarios mínimos, asignaciones familiares, reglamentación de los sindicatos y tribunales de conciliación y arbitraje de los conflictos.

La ley 10.449, del 12 de noviembre de 1943, creó los Consejos de Salarios y definió el alcance, la organización, el funcionamiento y los propósitos de la institución. 
La norma refiere exclusivamente al comercio, la industria y los servicios privados. La discusión parlamentaria rechazó la extensión de los Consejos de Salarios al medio rural por considerarla como una introducción de la lucha de clases en el campo, que rompe la armonía entre el patrón y los peones. No tuvo tampoco en cuenta a los funcionarios públicos, sometidos a procedimientos clientelares de incorporación, remuneraciones y retiro por los partidos políticos. Dejó fuera, en fin, también las múltiples formas de trabajo familiar y no asalariado. Los Consejos de Salarios comprenden sólo a los trabajadores de la actividad privada urbana y los separan de otros vinculados por formas de explotación distintas.

La institución reproduce las formas de organización creadas por los trabajadores y procura suprimir sus expresiones autónomas. La ley indica al Poder Ejecutivo que clasifique aquellas actividades por grupos y en cada grupo funcione un Consejo de siete miembros: tres designados por el gobierno, dos electos por los patronos y dos por los obreros. No considera a los trabajadores como sujeto activo sino como objeto de representación, ignora las organizaciones existentes y procura reemplazarlas por una elección de delegados. La norma regula cuidadosamente el procedimiento electoral, define las condiciones exigidas para ser representante y dispone que sean designados por el Poder Ejecutivo si alguna de las partes no concurre a la elección. Luego de fuertes discusiones en torno a la participación, los sindicatos optaron por intervenir en las elecciones de delegados con sus propios candidatos (RODRÍGUEZ, 1966). Por esta vía, las organizaciones obreras penetraron en las instituciones del estado y convirtieron en práctica corriente obviar la elección, designando directamente a los representantes de los sindicatos.

Los Consejos de Salarios funcionan en forma descentralizada. El Poder Ejecutivo debe definir, en cada caso, el alcance profesional y territorial de su jurisdicción. La toma de decisiones requiere la presencia de los tres sectores, se efectúa por mayoría y sus resoluciones son obligatorias en todo el grupo de actividad definido. La ley no establece una relación paritaria entre el trabajo y el capital, ni tampoco impuso el predominio del estado. Su peculiar configuración produce una lógica de acuerdos sociales y atribuye al gobierno un papel arbitral. La mecánica de formación de mayorías permite que, en caso de desacuerdo, el Poder Ejecutivo pueda inclinar la balanza tanto hacia los trabajadores como los empresarios, pero también hace posible que prevalezcan los acuerdos entre los actores sociales, incluso contra la opinión del gobierno. 
La ley sólo admite una imposición del Poder Ejecutivo, de manera excepcional y con el propósito de aumentar los salarios, cuando un laudo sea "demasiado bajo". En la práctica, las negociaciones ocurrían previamente entre sindicatos y empresarios, y el Consejo de Salarios sólo se reunía después, con los delegados del gobierno, para formalizar los acuerdos (MANTERO, sin data).

El cometido de los Consejos de Salarios es fijar salarios mínimos. Cada Consejo debe clasificar las categorías de trabajadores de su rama de actividad y establecer los ingresos mínimos por categoría. La ley define el salario mínimo como "aquel que se considera necesario, con relación a las condiciones económicas que imperan en el lugar, para asegurar al trabajador un nivel de vida suficiente, a fin de proveer a la satisfacción de las necesidades físicas, intelectuales y morales" (artículo 1). Prescribe que los Consejos tengan "especialmente en cuenta para aumentarlos": las condiciones económicas del país, el poder adquisitivo de la moneda, la calificación del trabajador, el peligro para su salud y el rendimiento de la empresa. La norma refiere los salarios a las necesidades y promueve aumentos concertados, según las condiciones de la economía y las empresas.

Los Consejos de Salarios fueron, por veinticinco años, una institución clásica del estado uruguayo (LANZARO, 1986). Dirigen las aspiraciones de los trabajadores hacia una demanda de artículos de consumo de la producción local, en tanto que el estado administra los tipos de cambio y la oferta de dinero de la economía, provee servicios públicos y reprime a los elementos opuestos. La formación de una clase obrera masiva tuvo respuesta política en instituciones que la separan por grupos, subordinan las necesidades al desarrollo del capital y desplazan los antagonismos hacia el estado, como mediador de los conflictos. Sin embargo, la circulación de las luchas desbordó las divisiones en una tendencia a articular las distintas facetas del trabajo; necesidades y deseos de la población chocaron con los límites del capital, empujaron las mediaciones estatales y constituyeron sujetos políticos antagónicos.

La primera reacción fue la represión del estado. Desde 1968, el gobierno pasó a fijar los salarios y empleó al ejército contra los sindicatos. A continuación, la dictadura militar impuso la autoridad absoluta de las patronales, persiguió la actividad sindical y administró una devaluación continua de la fuerza de trabajo durante la década del setenta. El decreto-ley 14.791 , del 8 de junio de 1978, sancionó estas prácticas atribuyendo al Poder Ejecutivo la facultad de establecer las retribuciones y categorías laborales de la actividad privada. 
La segunda respuesta fue la desregulación del mercado. Los Consejos de Salarios reaparecieron durante la transición democrática, para reordenar las relaciones laborales mientras persistía la administración del salario (FILGUEIRA, 1991), pero, finalmente, prevaleció la retirada del estado del mercado de trabajo. Los gobiernos democráticos abandonaron tanto la fijación de salarios como la organización de la negociación colectiva. El enfoque predominante rechaza los salarios mínimos y la legislación laboral como factores que dificultan los ajustes del mercado. Esperan que la desregulación disminuya los costos del trabajo y conduzca a aumentar la demanda de empleo.

\section{Los Consejos de Salarios de la izquierda}

Después de un largo eclipse, los Consejos de Salarios fueron restablecidos en el año 2005 por el gobierno del Frente Amplio.

Estos Consejos de Salarios de comienzos del siglo XXI, sin embargo, responden a una composición del trabajo distinta a la del período clásico. Los estudios destacan la difusión de la precariedad desde la década del noventa (cf. SUPERVIELLE y QUIÑONES, 1999). La flexibilización laboral, la tercerización de actividades y la implicación con las empresas disgregaron la figura del trabajo como un sujeto masivo frente al capital. La relación laboral no se limita a algo que ocurre entre el trabajador y el patrón dentro de la fábrica. El mando sobre el trabajo se extiende como un control de la cooperación productiva en la sociedad. Los conflictos envuelven figuras diversas, en todo el arco de la reproducción social y adquieren formas políticas. Desaparecieron las organizaciones masivas, los sindicatos se reducen a los sectores formales y surgen formas particulares de gestión de necesidades comunes. La izquierda, los sindicatos y otras organizaciones resistieron las políticas neoliberales apelando a la intervención directa de la ciudadanía. Estos lazos incluyeron tensiones, donde las organizaciones sociales amenazaron con desbordar a la izquierda y esta con sustraerse, acordando con los demás partidos. No obstante, fueron decisivos tanto para dar eficacia política a las resistencias sociales como para canalizar electoralmente el malestar social a favor del Frente Amplio (IBARRA, 2005).

La izquierda respondió, desde el gobierno, a esta composición del trabajo poniendo fin a la desregulación y reorganizando los Consejos de Salarios. 
ElFrente Amplio criticó los efectos negativos de la desregulación. Señaló que, lejos de aumentar el empleo, en realidad, redujo los salarios, afectó las condiciones de trabajo y debilitó a los sindicatos. Sus enfoques presentan al trabajador como la parte más débil, consideran que el mercado acentúa los desequilibrios a favor del capital y requieren la mediación del estado, no para suprimir, sino para equilibrar la relación. El rechazo de la informalidad no equivale, sin embargo, a una crítica de la organización del trabajo. "No es posible confundir la flexibilización en el plano de la organización de la empresa con la desregulación de las leyes laborales", dice el ministro de Trabajo (Eduardo Bonomi, interpelación parlamentaria, 26 de febrero del 2008). Terminar con la desregulación no significa volver a la situación anterior, sino regular la nueva composición del trabajo.

A pocos días de asumir el mando, el Frente Amplio convocó a los Consejos de Salarios. El decreto 105, del 7 de marzo del 2005, invoca como fundamentos no sólo la vigencia de la ley de 1943, sino también del decreto-ley 14.791, que sancionó la fijación de los salarios por la dictadura militar. Esta apelación simultánea a normas opuestas indica, desde el principio, que no se trata simplemente de restaurar la institución clásica. Pone en marcha una estrategia más compleja que modifica, en su implementación, el alcance, la organización, el funcionamiento y los propósitos de los Consejos de Salarios.

En primer lugar, el gobierno de la izquierda extendió la negociación colectiva. Reorganizó los Consejos de Salarios en el comercio, la industria y los servicios privados, incluyó a los trabajadores rurales y creó también ámbitos de negociación particulares con los funcionarios públicos de la administración central, las empresas del estado y la enseñanza pública. Según Notaro (2007), la negociación colectiva del año 2006 incluyó a 440 mil trabajadores de la actividad privada urbana, 150 mil funcionarios públicos y 80 mil asalariados rurales. Sin embargo, del total de trabajadores privados, deduce un treinta por ciento no registrados. Fuera del sistema quedan, además, $250 \mathrm{mil}$ trabajadores por cuenta propia, $95 \mathrm{mil}$ del servicio doméstico, 90 mil trabajadores rurales no asalariados y los funcionarios públicos de la justicia y los gobiernos departamentales.

La negociación colectiva alcanzó al conjunto de las actividades económicas, pero los Consejos de Salarios son una institución parcial, que incluye solamente a los trabajadores formales por separado de los precarios. 
En segundo lugar, el Frente Amplio incorporó a las organizaciones sociales y protegió especialmente a los sindicatos. Creó un Consejo Superior Tripartito y un Consejo Rural, integrados por el gobierno, la central sindical y las cámaras empresariales con el cometido de clasificar los grupos de actividad y organizar la negociación colectiva. Los decretos 138 y 139 , del 19 de abril del 2005, establecieron veinte Consejos de Salarios urbanos y tres rurales, con cerca de doscientos subgrupos particulares. Su integración siguió la práctica de obviar la elección y designar directamente a los delegados de las organizaciones representativas. Por otra parte, la izquierda suprimió la intervención policial contra la ocupación de lugares de trabajo y legisló un fuero sindical, que ampara a las organizaciones de la persecución patronal. La ley 17.940, del 2 de enero del 2006, establece la nulidad de todo acto antisindical y dispone la reposición de la situación anterior. La incorporación de las organizaciones y la protección legal fomentaron el crecimiento de los sindicatos. Juan Castillo, dirigente del PIT-CNT, estimó que, a los 140 mil trabajadores sindicalizados a comienzos del año 2005, se agregaron entre cuarenta y cincuenta mil luego de la instalación de los Consejos de Salarios, lo que equivale a un 33 por ciento de aumento de la afiliación ( $E l$ Observador, 10 de julio del 2005).

La izquierda incorporó las organizaciones de trabajadores y empresarios a las instituciones del estado y protegió especialmente a los sindicatos. Fracasó, en cambio, la tentativa de acordar un sistema de prevención y resolución de conflictos. Sindicatos y patronales rechazaron, con fundamentos opuestos, el decreto elaborado por el Ministerio de Trabajo y preservaron su autonomía del estado en la gestión de los conflictos.

En tercer lugar, el FrenteAmplio modificó el funcionamiento de los Consejos de Salarios con procedimientos ajenos a la ley y las prácticas clásicas, que sólo cuentan con antecedentes en la transición democrática. Por un lado, estableció plazos y porcentajes de ajuste de salarios simultáneos y uniformes para toda la actividad económica. Estas pautas generales no son objeto de negociación con las organizaciones sociales; son definidas previamente por el Poder Ejecutivo y anunciadas a sindicatos y empresarios como los marcos que restringen la negociación. Por otro lado, el gobiemo requiere que los acuerdos de cada Consejo sean ratificados por decretos de los Ministerios de Economía y de Trabajo, como condición de validez general. La llamada "homologación" del Poder Ejecutivo actúa como un control posterior para evitar que los actores sociales acuerden entre sí por fuera de las pautas gubernamentales (MANTERO, sin data). 


\section{HUMANAS}

Según Rodríguez, Cozzano y Mazzuchi (2006), la conflictividad en el año 2005, con la instalación de los Consejos de Salarios, fue la más baja de los últimos diez años. En el 2006, la central sindical rechazó los porcentajes de ajuste, aunque no cuestionó los procedimientos gubernamentales. Los conflictos se duplicaron con respecto al año anterior, incluyendo acciones generales por aumento de las pautas y mejoras presupuestales, pero se dispersaron con distintos resultados particulares. Sólo un 9 por ciento de los acuerdos superó las pautas gubernamentales, el 32 por ciento alcanzó los niveles máximos, un 34 por ciento quedó por debajo de.ellos y el resto acordó aumentos diferenciados a favor de las categorías inferiores. Finalmente, la ronda del 2008 vino precedida de reuniones donde la central sindical y las cámaras empresariales, por separado, plantearon directamente al presidente de la República sus aspiraciones con respecto a las pautas de gobierno.

Los mecanismos complementarios de las pautas de ajuste y la homologación de los acuerdos modifican la relación entre los actores e invierten la lógica de funcionamiento de los Consejos de Salarios. Desplazan la iniciativa hacia el gobierno, que dispone de la primera y la última palabra de la negociación, y reducen la participación social a una implementación particular según las condiciones de cada actividad. No producen acuerdos sociales con la mediación de los conflictos por el estado sino que, al contrario, imponen un comando del estado que limita los acuerdos y contiene los conflictos sociales.

Por último, esta imposición del Poder Ejecutivo no es excepcional ni va orientada a aumentar los salarios, como prescribe la ley; por el contrario, es constitutiva del funcionamiento actual de los Consejos de Salarios y tiene el propósito de limitar los incrementos salariales. Se efectuaron tres rondas de negociación en el período. El Poder Ejecutivo determinó, en todos los casos, la duración de los acuerdos, los porcentajes de aumento y los plazos de ajuste:

- La primera ronda del 2005 estableció acuerdos de un año, por porcentajes que incluyen la inflación más un aumento real entre dos y cuatro por ciento, distribuido en ajustes semestrales.

- La segunda, del año 2006, fijó acuerdos de 18 meses según la inflación proyectada y un incremento real entre 3,5 y 5,5 por ciento, con ajustes semestrales. 
- Las pautas del 2008 plantean dos posibilidades: una, con vigencia por dos años, un incremento real entre uno y tres por ciento anual, con ajustes semestrales; y la otra, por treinta meses, un aumento máximo del cinco por ciento anual y ajustes anuales.

Las pautas del gobierno limitan los aumentos de salarios dentro de estrechos márgenes, extienden cada vez más la duración de los acuerdos con propósitos de estabilización y procuran dilatar también los plazos de ajuste para retardar la inflación. Las cámaras empresariales favorecen la administración del salario por el gobierno, aunque recelan del fortalecimiento de los sindicatos como una amenaza al mando sobre el trabajo. Los sindicatos valoraron positivamente el restablecimiento de la negociación colectiva y la protección legal, como una satisfacción de sus propias demandas, y postergaron sus aspiraciones de mejora salarial al fortalecimiento de la organización.

De este modo, el Frente Amplio combinó dos formas de regulación inicialmente opuestas: la administración del salario por el gobierno se efectúa a través de la negociación colectiva, en tanto que esta se desenvuelve dentro de marcos acotados por la autoridad.

En suma, una composición del trabajo caracterizada por la precarización tuvo respuesta política en una reorganización de los Consejos de Salarios, que incluye a los sectores formales por separado de los precarios, incorpora a las organizaciones sociales y administra los salarios como una variable dependiente de la política económica, subordinada a objetivos de inflación y equilibrio fiscal.

\section{Conclusiones}

El gobierno del Frente Amplio puso fin a la desregulación del mercado de trabajo y restableció los Consejos de Salarios. No se trata simplemente de la actualización de una institución clásica del estado uruguayo. Por el contrario, responde a los cambios en la composición del trabajo con una inversión de las relaciones con el estado y el capital dentro de la lógica de la institución.

Los Consejos de Salarios de mediados del siglo XX fueron la reacción política a la formación de una clase obrera masiva. Procuraron organizar a ese sujeto por separado de otros trabajadores, suprimir sus expresiones autónomas y subordinar sus necesidades y deseos al desarrollo de la acumulación de capital. 
En su forma clásica, los Consejos de Salarios institucionalizan la relación del trabajo con el capital y desplazan los antagonismos hacia el estado como mediador de los conflictos.

A principios del siglo XXI, los Consejos de Salarios de responden a una composición del trabajo distinta, caracterizada por la precarización. Agrupan a los trabajadores formales por separado de los precarios, incorporan sus organizaciones sociales y subordinan sus necesidades y deseos a objetivos de inflación y equilibrio fiscal. Los Consejos de Salarios organizados por el gobierno del Frente Amplio institucionalizan la relación del trabajo con el capital, pero el estado no actúa como mediador sino como comando, que contiene los antagonismos y limita los conflictos.

En fin, una relación regulada envuelve tanto estabilidad como potencialidades de ruptura. Como vimos, la institución clásica fue desbordada por la circulación de las luchas entre las diversas facetas del trabajo, las aspiraciones de la población chocaron con los límites del capital, empujaron las mediaciones estatales y formaron sujetos políticos antagónicos. También los actuales Consejos de Salarios son atravesados por necesidades y deseos que chocan con los límites de la política económica, rechazan la precariedad y tienden a autonomizarse del mando. El resultado dependerá del curso de las luchas políticas.

\section{Referencias bibliográficas}

BANCOMUNDIAL. Informalidad: escape y exclusión. Washington: Banco Mundial, 2007.

BOYER, R. Les institutions dans la théorie de la regulation. Paris: CEPREMAP, 2003.

El Observador. Montevidéu, 10 de julio del 2005.

ERMIDA, O. U. La nueva legislación laboral uruguaya. IUSLabor 4/2006, Barcelona: Universitat Pompeu Fabra, 2006.

ERRANDONEA, A. y COSTABILE, D. Sindicato y sociedad en Uruguay. Montevidéu, Fundación de Cultura Universitaria, 1969.

FILGUEIRA, F. El movimiento sindical en la encrucijada. Revista Uruguaya de Ciencia Política, Montevidéu, n.4, 1991. 
IBARRA, L. El plebiscito del agua: nuevas alianzas, nuevas instituciones y nuevos desafios. In: BUQUET, D. (Coord.). Las claves del cambio. Montevidéu: Banda Oriental, 2005.

LANZARO, J. Sindicatos y sistema político. Montevidéu: Fundación de Cultura Universitaria, 1986.

LIPIETZ, A. El mundo del postfordismo. Ensayos de economía, Medelín, n.12, v.7, 1997.

MANTERO, O. La llamada "homologación" y otras formas de intervención del Poder Ejecutivo en las resoluciones de los consejos de salarios. Montevidéu: Instituto de Derecho del Trabajo, Universidad de la República, sin data.

NEGRI, A. Arqueología y proyecto: el obrero masa y el obrero social. In: Crisis de la política. Buenos Aires: El cielo por asalto, 2002.

NOTARO, J. Los Consejos de Salarios en el Uruguay. Montevidéu: Instituto de Economía, 2007.

RODRÍGUEZ, H. Nuestros sindicatos. Montevidéu: Centro de Estudiantes de Derecho, 1966.

RODRÍGUEZ, J. M.; COZZANO, B. y MAZZUCHI, G. Las relaciones laborales en el año 2006. Montevidéu: Universidad Católica del Uruguay, 2006.

SUPERVIELLE, M. y QUIÑONES, M. La instalación de la flexibilidad en Uruguay. Montevidéu: Facultad de Ciencias Sociales, Departamento de Sociología, 1999.

TRONTI, M. Obreros y capital. Madrid: Akal, 2001.

WORLD BANK. Workers in an integrating world. World Development Report. Washington: World Bank, 1995. 